\title{
Monitoramento e supervisão do Núcleo de Apoio à Saúde da Família (NASF) em uma região administrativa do Distrito Federal utilizando-se análise de entrevistas
}

\author{
Monitoring and supervision of the Support Centre for Family Health (NASF) in an administrative region of the Distrito Federal \\ using analysis of interviews
}

\section{Seguimiento y supervisión del Núcleo de Apoyo a la Salud Familiar (NASF) en una región administrativa del Distrito Federal mediante el análisis de entrevistas}

Michelline Ribeiro Rodriguez. Escola Superior de Ciências da Saúde (ESCS). Brasília, DF, Brasil. michellineribeiro@yahoo.com.br (Autora correspondente) Mônica Alvares Leão. Escola Superior de Ciências da Saúde (ESCS). Brasília, DF, Brasil. monica_leao@hotmail.com

Nubia Katia Teixeira de Souza. Escola Superior de Ciências da Saúde (ESCS). Brasília, DF, Brasil. nubiakatiat@yahoo.com.br

\section{Resumo}

Objetivo: Analisar o monitoramento e a supervisão das ações do Núcleo de Apoio à Saúde da Família (NASF) em uma região administrativa do Distrito Federal (DF), Riacho Fundo II. Métodos: Foram realizadas entrevistas semiestruturadas com cinco gestores do NASF nas esferas administrativas Regional, Distrital e Federal. Essas entrevistas foram gravadas, transcritas e feita análise de conteúdo de Bardin. Resultados: Não há um sistema de registro que contemple todas as ações que o NASF realiza. Percebe-se ausência de uniformidade na forma de supervisão do núcleo pelos órgãos responsáveis devido a um ineficiente fluxo de informações sobre o trabalho do NASF nas três esferas hierárquicas. Conclusão: A recente implantação do NASF no Distrito Federal e as dificuldades inerentes a essa etapa destacaram-se como principais fatores para a baixa qualidade dos registros de produção e a ausência de indicadores de avaliação para o NASF.

\section{Abstract}

Objective: To analyze the monitoring and supervision of the actions of the Support Centre for Family Health (NASF) in an administrative region of Distrito Federal (DF), Riacho Fundo II. Methods: Semi-structured interviews were conducted with five NASF managers who were responsible for its management at the Regional, District, and Federal levels. These interviews were recorded, transcribed, and analyzed according to Bardin's Content Analysis Method. Results: There is no registration system that includes all actions performed by NASF. Also, there is lack of uniformity in the supervision pattern used by the responsible bodies, due to inefficient flow of information regarding the work of this centre throughout the three hierarchical levels. Conclusion: The recent implementation of NASF in Distrito Federal was considered the major factor behind the poor quality of production registers and the absence of evaluative indicators of NASF activities.

\section{Resumen}

Objetivo: analizar el seguimiento y supervisión de las acciones del Núcleo de Apoyo a la Salud Familiar (NASF) en una región administrativa del Distrito Federal (DF), Riacho Fundo II. Métodos: se realizaron entrevistas semiestructuradas con cinco gerentes del NASF responsables por su gestión a nivel Regional, Distrital y Federal. Estas entrevistas fueron grabadas, transcritas y su contenido analizado con el método de Bardin. Resultados: no hay un sistema de registro que incluya todas las acciones realizadas por el NASF. Además, hay una falta de uniformidad en la forma de supervisión del núcleo por los órganos responsables debido a un ineficiente flujo de informaciones sobre el trabajo del NASF en los tres niveles jerárquicos. Conclusión: la reciente implantación del NASF en el Distrito Federal y las dificultades inherentes a esa etapa se destacaron como los principales factores responsables de la baja calidad de los registros de producción y de la ausencia de indicadores de evaluación para el NASF.

Keywords:

Management Indicators Health Management Primary Health Care

Palabras clave: Indicadores de Gestión Gestión en Salud Atención Primaria de Salud 


\section{Introdução}

A avaliação como componente da gestấo em saúde tem hoje um reconhecimento que se traduz na existência de múltiplas iniciativas voltadas para sua implementação nas diversas dimensóes do Sistema Único de Saúde (SUS). Tendo como propósito fundamental dar suporte aos processos decisórios no âmbito do sistema de saúde, deve subsidiar a identificação de problemas e a reorientação de ações e serviços desenvolvidos, avaliar a incorporação de novas práticas sanitárias na rotina dos profissionais e mensurar o impacto das ações implementadas pelos serviços e programas sobre o estado de saúde da população. ${ }^{1}$

As atividades de avaliação realizadas a partir das informaçôes produzidas no cotidiano da atenção, embora sejam insuficientes para apreender todas as mudanças desejáveis, são essenciais para a orientação dos processos de implantação, consolidação e reformulação das práticas de saúde, na medida em que permitem monitorar a situação de saúde da população, o trabalho em saúde e os resultados das açóes. ${ }^{2}$ A especificidade do monitoramento está no recurso de um sistema de informação para acompanhar a operacionalização de uma intervenção. O desenho do sistema de monitoramento é parte integrante do planejamento das açóes, devendo contemplar aspectos nucleares da execução do trabalho previsto para alcançar os objetivos da intervenção. ${ }^{3}$

A Estratégia Saúde da Família (ESF) foi concebida com o objetivo de reorganizar a Atenção Primária à Saúde (APS) para o enfrentamento e a resolução dos problemas de saúde identificados em uma dada população adscrita. ${ }^{4}$ Também fundamentado na reestruturação do SUS, foi criado, em 2008, o Núcleo de Apoio à Saúde da Família (NASF) com o escopo de apoiar a ESF e a rede de serviços. A portaria n. ${ }^{\circ}$ 154/08 destaca que o NASF pode ter duas modalidades: "NASF I, constituído de no mínimo cinco profissionais de nível superior e a que se vincula entre oito a vinte equipes de Saúde da Família; e o NASF II, constituído por três profissionais de nível superior e vinculado a no mínimo três equipes de saúde."5

A composição profissional deve ser definida pelos próprios gestores municipais e as equipes de ESF, mediante critérios de prioridades identificadas a partir das necessidades locais e da disponibilidade de profissionais de cada uma das diferentes ocupações. ${ }^{6}$

Os indicadores existentes na APS não são apropriados para avaliar as ações do NASF, sendo insuficientes para responder a muitas questôes e orientar as açôes da APS, pois o modelo de atenção vigente, baseado na ESF, requer indicadores voltados para a atenção integral dos pacientes, em toda sua dimensão biopsicossocial. Há necessidade de se institucionalizar a avaliação nos serviços de saúde, porém faltam metodologias e instrumentos para este fim, uma das principais dificuldades que vêm sendo apontadas nesta área. ${ }^{7}$

Fundamentado na premissa da inovação do NASF, assim como na ausência de indicadores ou fichas de produção específicas ao trabalho desses profissionais, surgiu o interesse em aprofundar os conhecimentos sobre sua estrutura de trabalho por meio da seguinte pergunta: Como se realiza a supervisão e o monitoramento das açôes da Equipe NASF no Riacho Fundo II?

O Riacho Fundo é uma das 19 regióes administrativas do DF, fundada em 1990, contando, na data de realização do estudo, com aproximadamente 44 mil habitantes. A renda domiciliar média da população da cidade era de R \$2.212,00; 99,2\% dos domicílios tinham abastecimento de água e esgotamento sanitário pela rede geral, e serviço de limpeza urbana. Possuía como assistência à saúde um total de 14 equipes de ESF, distribuídas em cinco unidades de saúde, sendo a sede o Centro de Saúde número quatro, local que também abrigava o único NASF da região, que prestava assistência à todas as equipes.

\section{Métodos}

Trata-se de uma pesquisa qualitativa realizada com gestores do NASF nas três esferas de governo - regional, distrital e federal -, no ano de 2011. Realizou-se análise descritiva por meio de entrevistas semiestruturadas compostas de perguntas abertas, visando a analisar as formas de supervisão e monitoramento da equipe NASF na região administrativa do Distrito Federal, Riacho Fundo II, além de verificar a existência de fichas de produção para o NASF.

A amostra de conveniência foi composta por cinco servidores que atuavam de forma direta na coordenação e na supervisão do NASF, nos seguintes locais: Diretoria de Atenção Básica (DAB) do Ministério da Saúde (MS); Diretoria de Atenção Primária à Saúde (DIAPS); Gerência de Monitoramento e Avaliação da Secretaria de Saúde do DF (GEMA); Gerência do 
Centro de Saúde 4 do Riacho Fundo II. Essa regional de saúde foi escolhida por contar com equipe de NASF II completa e estar implantada em uma área com cobertura total no que diz respeito à ESF.

As entrevistas foram gravadas, transcritas e posteriormente analisadas. Para apreciação dos dados coletados, foi utilizada a análise de conteúdo de Bardin, ${ }^{8}$ que tem como objetivo analisar as características de uma mensagem através da comparação destas mensagens para receptores distintos ou em situaçôes diferentes com os mesmos receptores. Para tanto, utilizou-se a leitura analítica como instrumento para a realização da análise, sendo primeiramente realizada uma pré-análise, composta pela análise textual e temática, e pela análise propriamente dita. ${ }^{9} \mathrm{Na}$ sequência, foi feita a categorização dos elementos para a análise, além do tratamento destas informaçóes. Após esta fase, seguiu-se a exploraçáo consubstancial do material e, por fim, fez-se o tratamento dos resultados.

A inferência e a interpretação dos resultados tiveram como referência as três categorias extraídas da análise: 1) Problemas relacionados à implantação do NASF no DF; 2) Formas de supervisão dos NASFs e sua abrangência; 3) Visão sobre a criação de registro de produçáo e indicadores do NASF. A pesquisa foi aprovada pelo Comitê de Ética da SES/DF protocolo 437/10 e todos os participantes assinaram o Termo de Consentimento Livre e Esclarecido (TCLE), ficando com uma cópia do mesmo. A pesquisa foi financiada pelo Ministério da Saúde através do Programa de Educação pelo Trabalho para a Saúde- PET-Saúde.

\section{Resultados e discussão}

\section{Categoria 1. Problemas relacionados à implantação do NASF no Distrito Federal}

A proposta de implantação do NASF no DF foi realizada em janeiro de 2009 , sendo que a primeira equipe só foi oficializada em março de 2010. Trata-se, portanto, de um projeto recente, característica esta que reflete a atual situação do núcleo. Houve consenso entre os entrevistados de que o NASF, devido à sua incipiência, ainda está em processo de estruturação e consolidação. Tal afirmação é compartilhada por autores como Fragelli, ${ }^{10}$ que relata que o NASF ainda está em processo de implantação e vem com o objetivo de ampliar a capacidade da APS, objetivo este que encontra, como grande desafio, modificar o processo de trabalho.

Para facilitar o processo de implantação, o MS elaborou uma cartilha indicando passo a passo as atividades a serem desenvolvidas: o primeiro passo é a elaboração de um projeto contendo diversas informaçóes, incluindo a definição do processo de avaliação do trabalho das equipes, a forma de acompanhamento do Pacto da Atenção Básica e a utilização dos sistemas nacionais de informação. ${ }^{11}$ A normativa prevista no Caderno de Atenção Básica - Diretrizes do NASF prevê que o projeto desenvolvido seja entregue para apreciação e aprovação pelo Conselho Distrital de Saúde. Posteriormente, a Secretaria de Saúde do DF envia o mesmo para o MS, que o qualifica para a implantação do NASF. ${ }^{5}$ Pelo que se observou na análise das entrevistas, as recomendaçóes para implantação não foram seguidas, pois não houve um planejamento adequado, conforme os extratos abaixo:

E1 - Algumas dessas equipes foram cadastradas. Na verdade eles pegaram esses profissionais e colocaram no NASF, mas assim... pra cadastrar. Não foi feito realmente uma pactuação com gestores, diretores, equipes ESF, nem coordenadores.

E2 - Não houve em 2009 uma capacitação até mesmo para saber o que é o NASF, como o NASF funciona.

Há necessidade de planejamento e capacitação adequada dos profissionais como pontos importantes no processo de implantação. Na cidade de Marília-SP, após a contratação dos profissionais para compor tais equipes, foi realizado um programa de acolhimento e capacitação destes para o trabalho a ser realizado, na lógica das ferramentas preconizadas pelo MS. ${ }^{11}$ A ausência de uma capacitação e integração entre os diversos profissionais envolvidos nas atividades do NASF é citada em muitos trechos das entrevistas como causa dos problemas enfrentados hoje por esse núcleo no DF.

E2 - Esses profissionais que foram chegando eles aproveitaram os especialistas que já existiam nos antigos Centros de Saúde. Mas que também não foi feita essa capacitação. 
E1 - A gente tem aí um problema enorme que é a formação desse profissional, sem capacitação, com desconhecimento do papel dele dentro do NASF e como atuar nessa perspectiva.

Foi também citada a falta de uma coordenação própria para o núcleo, ainda que vinculada à ESF, pois o mesmo está inserido na Subsecretaria de Atenção Básica, porém sem nenhum responsável por seu gerenciamento. Houve ainda diversos obstáculos a serem transpostos, como a mudança de governo e, consequentemente, dos gestores. Os entrevistados citaram essas dificuldades:

E3 - Não tinha uma coordenação responsável especificamente para o NASF.

E2 - Nós tivemos uma mudança de governo, mudou governador, mudou quase que todo mundo dos gestores tanto dos diretores. Então é o mesmo que começar tudo de novo.

O NASF já conta com uma coordenação no DF que, no momento da realização do estudo, estava trabalhando em função de organizar a implantação do Núcleo, objetivando sua estruturaçáo nos moldes preconizados pelo MS.

\section{Categoria 2. Formas de supervisão dos NASFs e sua abrangência}

Os registros de produção oficial, mencionados pelos níveis regional e distrital para as açóes dos profissionais do NASF, são feitos em uma ficha denominada Relatório de Produção e de Marcadores para Avaliação (PMA2), ${ }^{12}$ elaborada para preenchimento das atividades da ESF. Na PMA2, constam procedimentos realizados apenas pelo profissional médico e enfermeiro, porém essa ficha contém campos adicionais destinados às atividades de visita domiciliar, atendimento individual e atividade em grupo, realizados por 'outros profissionais de nível superior', sem especificar qual profissional.

E4 - O Registro é feito na PMA2, que é uma ficha que ainda está em discussão. É uma ficha da ESF, que eles [equipe NASF] anotam, assim, as consultas, os grupos, as visitas e os procedimentos.

\section{E3 - São os dados do PMA2 né, e elas [NASF] me passam os dados do PMA2, e é uma explicação geral.}

Essas fichas são preenchidas pelas equipes de ESF e enviadas para a Secretaria de Atenção Básica. Porém, verificou-se, nas entrevistas, a pouca utilidade da PMA2 como ferramenta de supervisão das equipes NASF. Tal fato foi atribuído à falta de recursos humanos para análise das mesmas, mas principalmente à ineficácia desse instrumento, o qual contém poucos campos para registros das açóes coletivas ou individuais. Isso fica claro nas falas que se seguem:

E4 - Na verdade a gente não faz muita coisa com isso [PMA2], pois as informaçôes são muito soltas e sem contextualização. Então normalmente isso fica arquivado. [...] E4 - Os formulários e sistemas de informaçóes que existem hoje, de fato são muito insuficientes para medir a atuação do NASF, pois estes instrumentos têm poucos campos específicos para poder fazer o registro das açôes coletivas ou individuais.

\section{E5 - A PMA2 não contempla as atividades do NASF, muito longe disso!}

Existe ainda a utilização, no nível regional, dos registros de produção individual, através do Boletim de Produção Ambulatorial (BPA), registrado pelos procedimentos do Sistema de Informação Ambulatorial (SIA), que funciona em nível nacional e é o mesmo programa utilizado no nível hospitalar e nas Unidades Básicas de Saúde (UBS). Neste programa, os demais profissionais atuantes na ESF registram sua produtividade e podem ser identificados a partir da Classificação Brasileira de Ocupação (CBO) do profissional, como segue:

E5 - Então o que se usa hoje pra tá se avaliando ou pra tá se monitorando o atendimento do NASF é o BPA através do $C B O$ e através do SIAB [Sistema de Informação da Atenção Básica], pela PMA2, mas só outros atendimentos, outros profissionais de Ensino Superior. Então vem no geral.

No MS, ainda não existe uma sistemática de avaliação e monitoramento do NASF, pois aquele adota uma visão generalizada sobre a supervisão deste núcleo. Esse órgão participa da implantação do NASF e o monitoramento é feito através do Cadastro Nacional do Estabelecimento de Saúde (CNES). Em relação às ações do NASF, a única fonte de registro é o SIA, através do $\mathrm{CBO}$ do profissional, o qual não contempla todas as açôes do NASF, somente registra os procedimentos realizados. Essas informaçóes ficam claras nas falas que se seguem: 
E5 - A gente tem o CNES... Toda Unidade Básica ela se cadastra e nessa hora vai dizer o seguinte: dentro dessa Unidade tem o NASF, ela consegue identificar pelo CNES. E a hora que ela fala que tem NASF, ela vai fazer o leque de profissionais que tem. [...] E5 - Então, assim, o único registro que a gente tem é pela Portaria 154 do NASF é o SIA, que é o Sistema de Informação Ambulatorial a nivel nacional.

Pelas entrevistas, inferiu-se que, para o MS, o que interessa é a existência ou não do NASF em uma determinada região e que a parte de supervisão das atividades dos profissionais que compóem o NASF deve ficar a critério de cada município que dispóe de total autonomia para fazê-la.

E5 - Os municípios têm toda liberdade, autonomia de gerar seus indicadores próprios, junto com o Pacto da Saúde, gerar seus indicadores próprios.

O município tem, juridicamente, uma função ampla na produção da informação, não devendo se restringir à simples coleta de dados. Segundo a Lei Orgânica da Saúde, são também de competência do município a organização, a produção e a coordenação do sistema de informação em saúde. ${ }^{9}$ Outra forma de supervisão verificada na análise das entrevistas é aquela desenvolvida pela coordenação do NASF no DF, na qual o monitoramento é realizado por meio de visitas programadas, indo a cada regional de saúde e diretamente com as equipes, realizando reunióes informais registradas em ata. As informaçóes relevantes são tratadas pela mesma coordenação para posterior análise.

Foi referida por tal coordenação a tentativa de elaboração de um modelo de relatório para que o trabalho desse núcleo pudesse ser acompanhado com maior precisão. $\mathrm{Na}$ ocasião do estudo, já haviam ocorrido diversas reunióes e a elaboração de alguns relatórios. Esses instrumentos foram relatados pela Diretoria Regional do Riacho Fundo II como ferramentas utilizadas por ela para supervisionar as açóes do NASF. As verbalizaçóes a seguir ilustram estas informaçóes:

E3 - A supervisão é feita quando a coordenação está indo lá, vendo, e trabalhando lá, no local junto com os profissionais do NASF, que é o que ela está fazendo. A coordenadora quase não pára nada aqui, ela passa o tempo todo nas regionais até estruturar. [...] E3 - Nós temos uma coordenadora responsável por esse núcleo. Ela faz reuniöes periódicas com cada categoria profissional ou grupo de profissionais, a fim de se estabelecer juntos processos de trabalho, metas, planos de serviços, verificarem problemas e instruir tais profissionais.

A necessidade de reunióes para coordenar o processo de gestáo reflete exatamente a atual situaçáo do NASF no DF, em processo de implantação. As diretrizes instituem que a implantação requer o estabelecimento de espaços rotineiros de reunião para pactuar e negociar o processo de trabalho: discussão de casos, definição de objetivos, critérios de prioridade, gestão das filas de compartilhamento (encaminhamento), critérios de avaliaçáo dos trabalhos e resolução de conflitos. ${ }^{5}$ Alguns municípios, frente à dificuldade de elaboração de indicadores que reflitam as açôes do NASF, também utilizam ferramentas, como reuniōes e relatórios para mencioná-las mais fielmente. ${ }^{13}$

Verificou-se que foi consenso entre os entrevistados que os instrumentos utilizados pelos diferentes órgãos para supervisão do NASF não contemplam realmente as atividades realizadas por esse núcleo. O que pode ser comprovado em várias falas:

E2 - A gente não tem nem a planilha, não tem nem o instrumento ainda que sirva a essa função.

E3 - A gente só consegue fazer uma avaliação superficial disso, do que é esperado. [...] E3-Vocês vão ver que hoje não tem procedimento de processo de trabalho do NASF. Vocês vão ver claramente que não existe, tá. Então é assim. É, não, não tem hoje. Porque também hoje a lógica do Sistema não é ver processo de trabalho.

Uma das dificuldades encontradas no processo de trabalho do NASF é a ausência de um sistema de informação que contemple o registro de atividades desenvolvidas nas áreas descentralizadas da ESF e isso limita o processo de planejamento em saúde dos profissionais e gestores. ${ }^{8}$ Ao entender que a informação representa um espaço importante para o desenvolvimento e a produção em saúde, é necessária a elaboração de um instrumento (ficha, software) para a coleta de dados, bem como a elaboração de um fluxo de informaçôes, processamento, definição de indicadores, análise, discussão e divulgação dos relatórios gerados por tal sistema. ${ }^{14}$

\section{Categoria 3. Visão sobre a criação de registros de produção e indicadores do NASF}

Embora não exista uma maneira eficaz de registro que contemple as açôes do NASF em nenhum âmbito administrativo, todos reconheceram a importância de um instrumento mensurável e eficiente para sua avaliação e gestão, e há uma mobilização de esforços nesse sentido. Entretanto, cada esfera está em um momento diferente em relação a esse assunto. 
Nos níveis Regional e Distrital, existem discussôes acerca da criação de um registro de produção, porém não há um produto concreto dessas discussóes. Na visão dos entrevistados, primeiro deve-se estruturar o NASF para depois se pensar em um indicador de processo das atividades.

Rodrigues et al. ${ }^{15}$ destacam que a mudança do modelo assistencial e sua respectiva incorporação ao trabalho multidisciplinar requerem um grande amadurecimento por parte dos profissionais, da gestão municipal e da população. Portanto, é durante o processo de implantação, com a experiência vivida, que se toma consciência das necessidades do serviço e como fazer adaptaçóes necessárias para melhorá-lo. Nesse sentido, foram citadas algumas tentativas de elaboraçáo de uma ficha de produção para o NASF:

E4 - Existe um estudo que já foi começado, mesmo antes da atual coordenaçâo, já se tinha começado um estudo pra se fazer um formulário. Já tem um formulário mais ou menos, né, estruturado, que não foi colocado em prática ainda, que foi definido através de uma comissáo, mas nem todo mundo tem conhecimento ainda, vai ter capacitação e tudo, mas ainda não teve de fato.

E3 - Foram feitas algumas discussóes sobre o tema (instrumentos de registro de produção para o NASF), mas ninguém fechou nada ainda. Estamos dando um passo de cada vez.

Qualquer que seja o registro de produção, os entrevistados reconheceram que este deve ser pactuado com todos os níveis de atenção à saúde, principalmente com os profissionais envolvidos diretamente no NASF.

Deve-se ter esse cuidado, pois foi relatada nas entrevistas a ineficácia de muitos indicadores de saúde para tomada de decisão, devido ao não comprometimento do profissional com a informação gerada e o consequente descrédito nela.

E4 - Mas qualquer tipo de informaçâo, tanto essa como as outras, tem muito pouca utilidade hoje na SES [Secretaria de Estado de Saúde]. Pois a SES vem de muitos anos, de uma prática de não utilização da informação para tomada de decisão. Aí cria-se um ciclo vicioso que é de 'como eu não utilizo a informação, não valorizo a informação, náa analiso e, portanto não critico a informaçãó. [...] E4 - Inclusive defendo que tais registros sejam propostos junto com esses profissionais, para tentar criar uma forma de avaliação.

Na visão da SES-DF, a gestão local (Centro de Saúde) deveria assumir o papel de supervisão das ações do NASF de sua área. Ressalta-se ainda a importância dos gestores distritais - Governo, Secretaria de Saúde - em organizar, apoiar a ESF, bem como o NASF, para que estes funcionem bem.

E3 - Temos a consciência clara que as regionais têm que assumir a gestäo local, têm que estar fortes e estruturadas para fazer essa gestão e aqui a gente tem que acompanhar o trabalho da regional como um todo.

O MS está em processo de reformulação de seus Sistemas de Informação (SI). Foi citada uma proposta de criação de um SI exclusivo para o NASF, além da reformulação do SIAB, que passaria a contemplar as ações do Núcleo. Estudos ${ }^{13}$ mostram as possibilidades de se readequar a SIAB para que sua utilidade seja ampliada, vindo a favorecer as tomadas de decisão referentes aos processos de promoção e educação em saúde, bem como aos cuidados dispensados na atenção regionalizada ${ }^{13}$. Isso foi observado por um dos entrevistados.

E5 - No Ministério está sendo reformulado com o SIAB e dentro dessa reformulação a gente tá criando esse de Sistema de Informação do NASF.

\section{Conclusão}

Apesar da escassa literatura existente para aprofundamento da discussão sobre o NASF, os resultados no presente artigo evidenciam que ainda não existe uma sistematização nas formas de supervisão, monitoramento e avaliação da Equipe NASF no Riacho Fundo II. Os registros das poucas açóes são feitos em fichas criadas com a finalidade de avaliação das equipes de ESF e baseadas em indicadores de produtividade centrados no modelo hospitalocêntrico. Estas escassas informações não são utilizadas como ferramenta de gestão em nenhum dos três níveis (regional, distrital e federal). Isso é atribuído ao fato de as informaçôes provenientes desses registros serem insuficientes. 
A recente implantação do NASF no Distrito Federal e as dificuldades inerentes a essa etapa destacaram-se como principais fatores para a situação dos registros de produção e a ausência de indicadores de avaliação para o núcleo. É consenso que as questôes relativas ao monitoramento necessitam ser aprimoradas posteriormente. Infelizmente, essa não é só uma realidade do DF e a maioria dos municípios ainda tem dificuldades para gerir o processo de trabalho do NASF, o que levanta a necessidade de mais pesquisas para encontrar soluçóes para esse problema.

\section{Referências}

1. Ministério da Saúde (BR), Departamento de Atenção Básica. Avaliação na Atenção à Saúde. Caminhos da Institucionalização. Brasília: Ministério da Saúde; 2005

2. Ministério da Saúde (BR), Departamento de Atenção Básica. Monitoramento na Atenção Básica de Saúde. Roteiros para Reflexão e Ação. Brasília: Ministério da Saúde; 2004

3. Ministério da Saúde (BR). Portaria n 154, de 24 de janeiro de 2008. Cria os Núcleos de Apoio à Saúde da Família - NASF. Diário Oficial da República Federativa do Brasil, 2008 mar. 4. Seção 1, n. 43, p. 38-42.

4. Ministério da Saúde (BR), Departamento de Atenção Básica. Indicadores Básicos para Saúde no Brasil: conceitos e aplicações. Brasília: Ministério da Saúde; 2002.

5. Ministério da Saúde (BR), Secretaria de Atenção à Saúde, Departamento de Atenção Básica. Diretrizes do NASF. Núcleo de Apoio a Saúde da Família. Brasília: Ministério da Saúde; 2009. (Série B. Textos Básicos de Saúde) (Cadernos de Atenção Básica, n. 27).

6. Conselho Nacional de Secretários de Saúde (BR). Acompanhamento e avaliação da Atenção Primária. Brasília: CONASS, 2004. Disponível em: http://189.28.128.100/dab/docs/geral/conass_documenta2.pdf

7. Bardin L. Análise de conteúdo. Lisboa: Editora 70; 2009.

8. Teixeira MB. Empoderamento de idosos em grupos direcionados à promoção da saúde. dissertação . São Paulo: Fundação Oswaldo Cruz, Escola Nacional de Saúde Pública; 2002. 105 p.

9. Silva CR, Gobbi BC, Simão AA. O uso da análise de conteúdo como uma ferramenta para a pesquisa qualitativa: descrição e aplicação do método. Organ Rurais Agroind. 2005;7(1):70-81.

10. Fragelli TBO. Análise das Competências Profissionais no Núcleo de Apoio à Saúde da Família. tese. Brasília: Universidade de Brasília; 2013.176 p.

11. Takano L, Faria ET, Garozi DE, Silva APP. NASF: experiência de Marília/SP na implantação do núcleo de apoio à saúde da família. $2^{a}$ Amostra Municipal de Produção em Atenção Básica / Saúde da Família; 2010.

12. Prefeitura de São Paulo, Secretaria da Saúde. Diretrizes e parâmetros norteadores das ações dos Núcleos de Apoio a Saúde da Família (NASF). São Paulo (SP); 2009. Disponível em: http://www.prefeitura.sp.gov.br/cidade/secretarias/upload/saude/arquivos/esf/diretrizes_nasf.pdf

13. Branco MAF. Sistemas de informação em saúde no nível local. Cad Saúde Pública. 1996;2(1):267-270. http://dx.doi.org/10.1590/S0102$311 \times 1996000200016$

14. Ministério da Saúde (BR). Pacto de Indicadores da Atenção Básica: instrumento de negociação qualificador do processo de gestão do SUS. Brasília: Ministério da Saúde; 2003

15. Rodrigues CG, Rodrigues FG, Wong LR. Os sistemas de informação em saúde: do processo de trabalho à geração dos dados em Minas Gerais. Diamantina: Editora UFMG; 2009. 